\title{
BMJ Open Prevalence and fluid management of dehydration in children without diarrhoea admitted to Kenyan hospitals: a multisite observational study
}

\author{
Sylvia Omoke (D) , ${ }^{1}$ Mike English, ${ }^{1,2}$ Jalemba Aluvaala (D) , , David Gathara, ${ }^{1}$ \\ Ambrose Agweyu, ${ }^{1}$ Samuel Akech, ${ }^{1}$ on behalf of the Clinical Information Network
}

To cite: Omoke S, English M, Aluvaala J, et al. Prevalence and fluid management of dehydration in children without diarrhoea admitted to Kenyan hospitals: a multisite observational study. BMJ Open 2021;11:e042079. doi:10.1136/ bmjopen-2020-042079

- Prepublication history for this paper is available online. To view these files, please visit the journal online (http://dx.doi org/10.1136/bmjopen-2020042079).

Received 04 July 2020 Revised 06 March 2021 Accepted 17 March 2021
A) Check for updates

(C) Author(s) (or their employer(s)) 2021. Re-use permitted under CC BY-NC. No commercial re-use. See rights and permissions. Published by BMJ.

${ }^{1}$ Health Services Unit, KEMRIWellcome Trust Research Programme, Nairobi, Kenya ${ }^{2}$ Department of Clinical Medicine, Nuffield, Oxford, UK ${ }^{3}$ Department of Paediatrics and Child Health, University of Nairobi, Nairobi, Kenya

Correspondence to

Sylvia Omoke;

somoke@kemri-wellcome.org

\section{ABSTRACT}

Objectives To examine the prevalence of dehydration without diarrhoea among admitted children aged 1-59 months and to describe fluid management practices in such cases.

Design A multisite observational study that used routine in-patient data collected prospectively between 0ctober 2013 and December 2018.

Settings Study conducted in 13 county referral hospitals in Kenya.

Participants Children aged 1-59 months with admission or discharge diagnosis of dehydration but had no diarrhoea as a symptom or diagnosis. Children aged $<28$ days and those with severe acute malnutrition were excluded.

Results The prevalence of dehydration in children without diarrhoea was 3.0\% (2019/68204) and comprised 15.9\% (2019/12702) of all dehydration cases. Only 55.8\% (1127/2019) of affected children received either oral or intravenous fluid therapy. Where fluid treatment was given, the volumes, type of fluid, duration of fluid therapy and route of administration were similar to those used in the treatment of dehydration secondary to diarrhoea. Pneumonia (1021/2019, 50.6\%) and malaria (715/2019, $35.4 \%$ ) were the two most common comorbid diagnoses. Overall case fatality in the study population was $12.9 \%$ (260/2019).

Conclusion Sixteen per cent of children hospitalised with dehydration do not have diarrhoea but other common illnesses. Two-fifths do not receive fluid therapy; a regimen similar to that used in diarrhoeal cases is used in cases where fluid is administered. Efforts to promote compliance with guidance in routine clinical settings should recognise special circumstances where guidelines do not apply, and further studies on appropriate management for dehydration in the absence of diarrhoea are required.

\section{BACKGROUND}

Dehydration in children is commonly secondary to diarrhoea, but other serious illnesses may also cause dehydration because of vomiting, reduced intake of fluids due to decreased appetite, increased insensible water loss due to fever, tachypnoea or compromised skin integrity. ${ }^{1}$ The WHO has guidelines for
Strengths and limitations of this study

- Focuses broadly on dehydration from non-diarrhoeal causes where concerns of potential harm with fluid therapy remain.

- Use of routine data across many hospitals therefore reflects real-world settings.

- Highlights that though dehydration is common in children without diarrhoea, there is in no specific guidance for fluid therapy in non-diarrhoeal cases.

- Some treatment might have been documented but not given, or administered but not documented.

- Use of registry data presenting possibility of ascertainment and selection biases.

fluid therapy in children aged 1-59 months with diarrhoea and dehydration (DD), which involves use of isotonic intravenous fluids or oral rehydration therapy, depending on the severity of dehydration ${ }^{2-5}$ (table 1 ). Usually, liberal volumes, which may include fluid boluses, are recommended for the more severe forms of DD. However, cautious fluid therapy has been recommended in cases of non-diarrhoeal illnesses due to safety concerns, ${ }^{6-8}$ and these fears have been supported by findings of the FEAST (Fluid Expansion as Supportive Therapy) study. The FEAST study is a large randomised controlled trial of alternative fluid management strategies for shock and impaired perfusion in febrile children in Africa ${ }^{49}$ which shows use of fluid boluses to be harmful for treatment of shock or impaired perfusion in children without diarrhoea. The burden of dehydration in the absence of diarrhoea in admitted children and fluid management approach adopted by clinicians in such cases is unclear in the study setting. Conditions such as pneumonia, malaria and meningitis are common causes of febrile illnesses, childhood admission and mortality in Kenya and in many 
Table 1 Guidelines for management of dehydration for children aged $\geq 1$ month (excluding severe malnutrition)

\begin{tabular}{ll} 
Classification & Clinical signs \\
\hline Shock & $\begin{array}{l}\text { All of; weak/absent pulse, altered consciousness AVPU* }<\text { A, } \\
\text { temperature gradient (cold hands), capillary refill }>3 \mathrm{~s} \text { plus } \\
\text { sunken eyes and slow skin pinch }\end{array}$ \\
$\begin{array}{l}\text { Severe } \\
\text { dehydration }\end{array}$ & $\begin{array}{l}\text { Two or more of; altered consciousness AVPU* }<\text { A or lethargy, } \\
\text { unable to drink, sunken eyes, return of skin pinch of } \geq 2 \mathrm{~s}\end{array}$
\end{tabular}

Recommended fluid management

Fluid bolus Ringer's lactate/normal saline $20 \mathrm{~mL} / \mathrm{kg}$

Plan C

Step 1: 30 mL/kg Ringer's lactate over 30 min if aged $\geq 12$ months OR over 1 hour if aged $<12$ months.

Step 2: $70 \mathrm{~mL} / \mathrm{kg}$ Ringer's lactate over 2.5 hours if aged $\geq 12$ months OR over 5 hours if aged $<12$ months

\begin{tabular}{|c|c|c|}
\hline $\begin{array}{l}\text { Some } \\
\text { dehydration }\end{array}$ & $\begin{array}{l}\text { Two or more of; drinks eagerly, sunken eyes, restlessness or } \\
\text { irritable, return of skin pinch for } 1-2 \mathrm{~s}\end{array}$ & $\begin{array}{l}\text { Plan B: } 75 \mathrm{~mL} / \mathrm{kg} \text { ORS (Oral Rehydration } \\
\text { Solution) over } 4 \text { hours }\end{array}$ \\
\hline No dehydration & $\begin{array}{l}\text { Less than two signs, not enough to classify as some or } \\
\text { severe dehydration }\end{array}$ & Plan A: 10 mL/kg ORS after every loose stool \\
\hline
\end{tabular}

Adapted from WHO Pocketbook of Hospital Care for Children: Guidelines for the Management of Common IIInesses with Limited Resources (Second Edition, 2013) ${ }^{2}$ and Kenya Basic Paediatric protocols (January 2016 Edition). ${ }^{5}$

${ }^{*} \mathrm{AVPU}$ is a scale used to measure and record a patient's level of consciousness. AVPU, alert, pain, unresponsive, verbal/voice.

resource-poor settings. ${ }^{10}$ These conditions may present with complications that may lead to dehydration even in the absence of diarrhoea where liberal fluid therapy may be harmful. ${ }^{11-14}$

In this study, we use routine data collected prospectively from 13 hospitals in Kenya ${ }^{15}$ to explore the prevalence of dehydration in the absence of diarrhoea, underlying diagnoses, fluid management practices and case fatality for children aged 1-59 months admitted with dehydration but without diarrhoea.

\section{METHODS}

\section{Study design and setting}

This is a multisite observational study that used routine in-patient data collected prospectively between October 2013 and December 2018. Data used in this study were collected from 13 hospitals involved in a collaborative effort, called the Clinical Information Network (CIN), to monitor and promote uptake of recommended inpatient management guidelines. Five of the hospitals are located in western Kenya, with high malaria transmission, whereas the other eight are within central Kenya, where there is no local transmission of malaria. ${ }^{16}$ Inception of the network, processes involved and data quality assurance procedures have been described previously. ${ }^{15} 1718$ In brief, all clinical assessments and decisions on treatment were made by routine hospital staff. On discharge or death of a patient, data were abstracted from medical records in each hospital by trained data clerks guided by standardised operating procedures. Data were abstracted to a REDCap (Research Electronic Data Capture) system-a non-proprietary data capture system. The data clerks abstracted information on each patient's clinical presentation, findings of physical examination, laboratory tests, admission diagnoses and treatment given from a standardised paediatric admission record, other medical notes and treatment sheet. Information on discharge diagnosis and outcomes was obtained from standardised paediatric discharge summary that has also been adopted across CIN hospitals. Use of standardised forms and standardised operating procedures minimised information bias during data abstraction.

\section{Study population}

We analysed data for children aged 1-59 months collected between October 2013 and December 2018. We excluded 10 months of data from a period characterised by health workers' strike between December 2016 and November 2017 because there was marked reduction in the number of admissions. ${ }^{19}$ We also excluded neonates and those with severe acute malnutrition (SAM), defined as a midupper arm circumference of $<11.5 \mathrm{~cm}$ for age $\geq 6$ months, a weight-for-height $z$-score of $<-3$ SD for children aged $<6$ months or a clinical diagnosis of SAM. Those with SAM were excluded because they had different management guidelines and dehydration was difficult to diagnose clinically, ${ }^{20}$ while for neonates, only minimal data (restricted to information on basic demographic characteristics, diagnoses and admission outcome that was required for routine national health information reporting) were collected and therefore detailed processes of care and admission characteristics could not be described. We also excluded data of non-medical cases including burns, and surgical cases that required specialised care.

The database was reviewed and those with a diagnosis of dehydration at admission or discharge but without diarrhoea as a diagnosis or presenting symptom at admission or discharge were identified. To confirm the absence of diarrhoea and to rule out data entry errors, we retrieved a random sample list of patients identified from two hospitals located near Nairobi, where the researchers were 
based, and one investigator with a medical background visited the hospitals and reviewed the medical records. The records were checked for the presenting symptoms, assessment during admission, in-patient medical notes from the ward rounds, admission and discharge diagnoses, and the data were entered into a separate database. Data collected from medical records were linked using unique patient identifiers to the wider CIN database. We compared findings recorded from medical records review to those in the CIN database specifically for diagnosis or history of diarrhoea.

\section{Data analysis}

We described the characteristics of the study population using proportions for binary, categorical and nominal data, means (SD) for normally distributed continuous data, and medians (and IQRs) for skewed or ordinal data. The proportion of children with dehydration diagnosis at admission or discharge but without diarrhoea was calculated overall and for each hospital. We also described fluid management practices (fluid type, volumes and duration), patient characteristics, and underlying diagnoses and case fatality.

\section{Patient and public involvement}

This study was done without patient involvement. However, the Ministry of Health, county health executives and all hospital management teams gave permission for this work to be developed and supported the implementation of the CIN. The study findings were disseminated to the hospital clinical teams in all the paediatric wards who provide care to the children for whom the CIN project was designed.

\section{RESULTS}

\section{Demographic characteristics of the study population}

A total of 68204 eligible children were admitted across the 13 study hospitals between October 2013 and December 2018. Figure 1 illustrates selection of the study population. The prevalence of dehydration in children without diarrhoea was $3.0 \%$ (2019/68204) (range 2.1\%-4.3\% across hospitals), and this comprised $15.9 \%$ (2019/12 702) of all dehydration cases. Children admitted in hospitals located in areas with high malaria transmission accounted for $45.2 \%(912 / 2019)$ of the study population. The median age was 14 months (IQR 7-26 months). Sex was

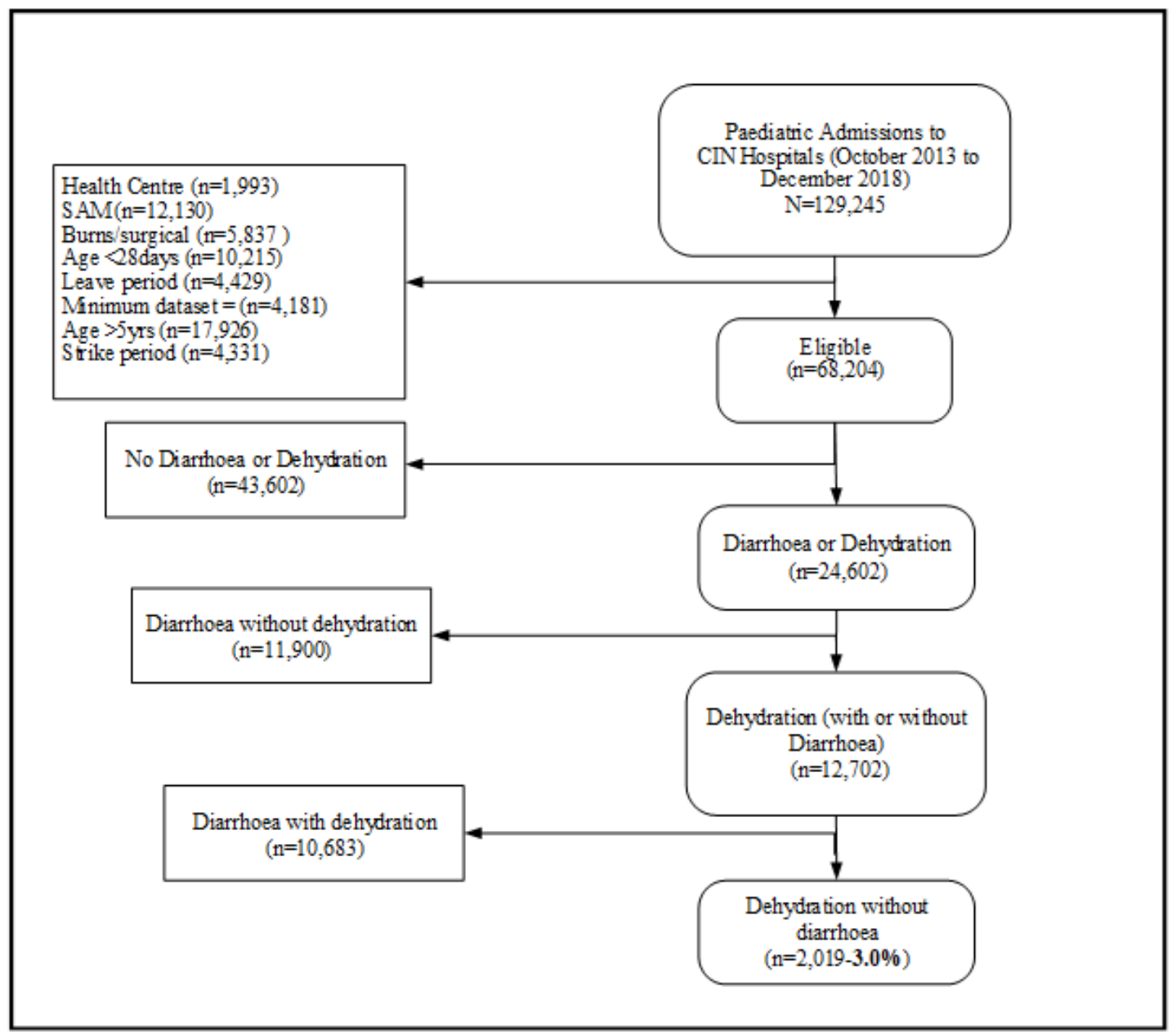

Figure 1 Flow diagram showing patient selection.

SAM, severe acute malnutrition. 
documented in $99.0 \%(2001 / 2019)$ of the population, $53.3 \%(1067 / 2001)$ of whom were male. More than half, $62.1 \%(1254 / 2019)$, were febrile (either had a history of fever or temperature $\geq 39^{\circ} \mathrm{C}$ at admission), while $16.3 \%$ (329/2019) had signs suggestive of impaired circulation shown by either weak pulse, capillary refill of $\geq 3 \mathrm{~s}$, temperature gradient or tachycardia (pulse rate $>180$ beats/min for children less than 12 months, $>160$ beats/ min for those aged 12 months and above but below 60 months). ${ }^{21}$

A total of 106 linked medical records were retrieved for validation from the two hospitals to ascertain the absence of diarrhoea diagnosis in recorded diagnosis or case notes. Review of the case notes showed that none had a diagnosis of diarrhoea or diarrhoea as symptom that may have been missed by the data clerk. Dehydration diagnosis without diarrhoea as recorded in the database and analysed here was therefore accurate.

Based on documented clinical diagnosis, some dehydration was the most common presentation $(1227 / 2019$, $60.8 \%)$, followed by severe dehydration (491/2019, $24.3 \%)$, and shock was least common (142/2019, 7.0\%). Dehydration was not classified in $7.9 \%$ (159/2019) of the cases. Characteristics of study participants are summarised in table 2. The major clinical diagnoses in this population were pneumonia $(50.6 \%, 1021 / 2019)$, malaria $(35.4 \%$, $715 / 2019)$, anaemia $(13.4 \%, 271 / 2019)$, clinically diagnosed meningitis $(11.9 \%, 241 / 2019)$ and moderate malnutrition $(10.5 \%, 212 / 2019)$. Most patients $(93.6 \%$, $1881 / 2019)$ had comorbidities, in addition to dehydration, whereby a coexistence of malaria and pneumonia was the most common $(12.3 \%, 248 / 2019)$, followed by anaemia and malaria $182 / 2019(9.0 \%)$, as shown in figure 2.

The overall case fatality was $12.9 \%(260 / 2019)$ and was directly related to the severity of dehydration-shock $(50.0 \%, 71 / 142)$, severe dehydration $(20.8 \%, 102 / 491)$ and some dehydration $(5.5 \%, 67 / 1227)$. Case fatality for unclassified dehydration was $12.6 \%(20 / 159)$.

Case fatality was $134(11.9 \%)$ in children who where prescribed any fluid compared with $126(14.1 \%)$ in those without any fluid prescribed. The case fatalities were $125(16.3 \%)$ and $135(10.8 \%)$, respectively, in patients prescribed intravenous fluids versus those without intravenous fluid prescriptions. Case fatality was lowest in children prescribed only oral fluids $(9,2.5 \%)$ and moderate for those with oral plus intravenous fluid prescriptions $(15,7.4 \%)$.

\section{Fluid management practices}

A total 55.8\% (1127/2019) of children with dehydration had a fluid prescription either intravenous or oral, as summarised in table 3. For those prescribed intravenous fluids, fluid bolus was prescribed in 3.8\% (77/2019), while maintenance fluid was prescribed in $14.7 \%$ (296/2019) cases. Oral rehydration therapy (plan A or B) without intravenous fluids was prescribed in $17.8 \%$ (359/2019) of cases. However, there were wide variations across hospitals
Table 2 Characteristics of study participants

\begin{tabular}{|c|c|}
\hline \multicolumn{2}{|l|}{ Population characteristics } \\
\hline Age (months), median (IQR) & $14(7-26)$ \\
\hline Sex, male (\%) & $1067 / 2001$ (53.3\%) \\
\hline Weight $(\mathrm{kg})$, mean \pm SD & $9.0 \pm 3.7$ \\
\hline MUAC (cm), median (IQR) & $13.7(12.5-15.0)$ \\
\hline Clinical characteristics & $\mathrm{n} / \mathrm{N}^{*}(\%)$ \\
\hline Capillary refill>2 s & 128/1287 (10.0) \\
\hline Sunken eyes & $546 / 1464$ (37.3) \\
\hline Delayed skin pinch & $627 / 1489(42.1)$ \\
\hline Weak pulse & $193 / 1471(13.1)$ \\
\hline History of ever & $1239 / 1614(76.7)$ \\
\hline Temperature $\geq 39^{\circ} \mathrm{C}$ & $240 / 1439$ (16.7) \\
\hline Temperature gradient & $132 / 1257(10.5)$ \\
\hline Impaired consciousness & 193/1594 (12.1) \\
\hline Cannot drink/breast feed & $431 / 1514(28.5)$ \\
\hline History of vomiting & $1058 / 1599(66.2)$ \\
\hline Impaired perfusion & $329 / 1578$ (20.9) \\
\hline Vomits everything & $661 / 1002(66.0)$ \\
\hline Age $<1$ year & $819 / 2019(40.6)$ \\
\hline $\begin{array}{l}\text { Non-diarrhoeal dehydration/total } \\
\text { dehydration }\end{array}$ & 2019/12 702 (15.9) \\
\hline Clinical diagnosis & $\mathrm{n}=2019, \mathrm{n}(\%)$ \\
\hline Pneumonia & $1021(50.6)$ \\
\hline Malaria & $715(35.4)$ \\
\hline Anaemia & $271(13.4)$ \\
\hline Meningitis & $241(11.9)$ \\
\hline Malnutrition & $212(10.5)$ \\
\hline Case fatality & $\mathrm{n} / \mathrm{N}(\%)$ \\
\hline Shock & $71 / 142(50.0)$ \\
\hline Severe dehydration & $102 / 491(20.8)$ \\
\hline Some dehydration & $67 / 1227(5.5)$ \\
\hline Unclassified dehydration & 20/159 (12.6) \\
\hline
\end{tabular}

*Denotes the study population was 2019; however, the denominator for the patients' characteristics varied based on documentation.

MUAC, mid-upper arm circumference.

in the use of intravenous fluids ranging from $22.1 \%$ to $55.4 \%$ or exclusive use of oral fluids ranging from $7.2 \%$ to $38.7 \%$. Nevertheless, use of intravenous fluid in general and fluid bolus was more common in children with severe forms of dehydration. However, notable cases with clinical signs of some dehydration received intravenous fluids $(33.1 \%, 406 / 1227)$, and a few received fluid boluses $(1.2 \%, 15 / 1227)$.

In the febrile group, $\mathrm{n}=1254(65.3 \%, 819 / 1254)$ had a fluid prescribed. Intravenous fluids were prescribed in $44.4 \%$ (557/1254), while oral fluid was prescribed in $32.6 \%$ (409/1254). Maintenance fluid was prescribed in $18.7 \%$ 


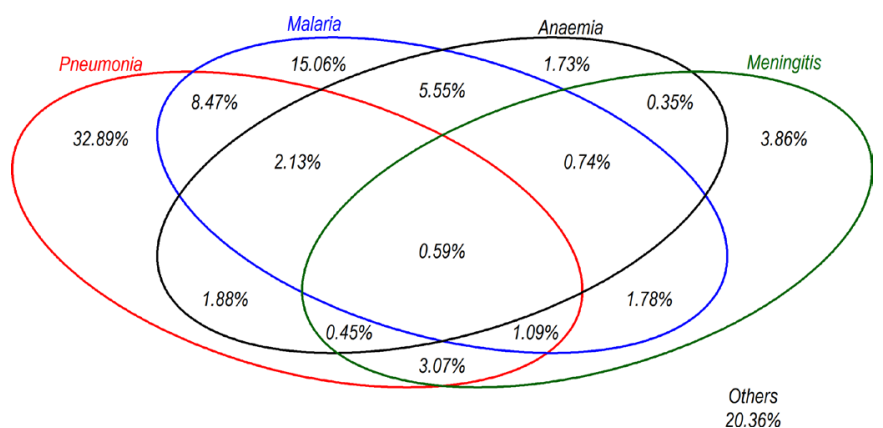

Figure 2 Venn diagram showing sets of combinations of top four comorbidities in addition to dehydration. Other diagnoses not in top four are denoted by 'others'.

(234/1254). Use of fluid bolus in this group was $3.6 \%$ (45/1254). Ringer's lactate and normal saline were the most commonly used intravenous fluids for treatment of shock (58/74, 78.4\%, and 9/74, 12.2\%). In participants with shock who had duration of fluid bolus documented, $86.2 \%$ $(25 / 29)$ received bolus fluid rapidly, and the rest, $13.8 \%$ $(4 / 29)$, received bolus over 1-2 hours. The median volume of fluid bolus was $20 \mathrm{~mL} / \mathrm{kg}$ body weight (IQR 20-30 mL). For treatment of severe dehydration, plan $\mathrm{C}$ was prescribed in 40.3\% (198/491); both steps 1 and 2 were prescribed in $23.6 \%(116 / 491)$ of the cases. For those younger than 12 months, the median duration of fluid treatment was 6 hours (IQR 5-6 hours), while in children 1 year and above, the median duration of fluid treatment was 3 hours (IQR 3-4 hours). The median volume given was $100 \mathrm{~mL} /$ $\mathrm{kg}$ body weight (IQR $93-100 \mathrm{~mL} / \mathrm{kg}$ ). Plan B was used in $26.8 \%(329 / 1227)$ of the participants with some dehydration; median volume given was $75 \mathrm{~mL} / \mathrm{kg}$ body weight (IQR $74-75 \mathrm{~mL} / \mathrm{kg}$ ) and was given over a median duration of 4 hours (IQR 4-4 hours).

\section{DISCUSSION}

The study was conducted to estimate the prevalence of dehydration from non-diarrhoeal illnesses and to establish fluid management practices used routinely by clinicians in the absence of clear guidance. This is the first study locally focusing broadly on dehydration from non-diarrhoeal causes since previous studies have concentrated on shock and impaired circulation, which are often adverse effects of untreated dehydration or a consequence of severe sepsis. ${ }^{78121422}$ Our study is important especially after concerns generated following findings of the FEAST trial, ${ }^{9}$ where fluid boluses, which are recommended for treatment of hypovolaemic shock secondary to diarrhoea, ${ }^{2}$ were shown to be harmful when used to treat shock in those with non-diarrhoeal illnesses. We therefore not only highlight the magnitude of a group of children who may need a different approach to fluid management but also those at risk of potentially harmful therapy.

Our study shows an overall low prevalence of dehydration in patients with non-diarrhoeal illnesses, but it still accounts for about $16 \%$ of all cases of dehydration, which is significant in a global context and important when considering children who may be exposed to potentially harmful treatment when liberal fluid therapy is used. Ascertainment through record linkage in two hospitals showed that these were not cases where diarrhoea was present as a symptom or diagnosis but missed at data entry. Fluid treatment, either oral or intravenous, is less frequently used to manage dehydration in the absence of diarrhoea $(55.8 \%, 1127 / 2019$, vs $78.2 \%$, $6696 / 8562$ ) in children with DD (data not shown, previously described) ${ }^{23}$ However, where fluid treatments are given, the route of administration, fluid type, duration of administration and volumes were similar to those recommended in DD. We found some discrepancy in the fluid regimen recorded in patients with various severities of dehydration. For example, there was use of fluid bolus in a child without shock, but we believe that this may be due to rapid change of clinical signs of dehydration. Such children without a diagnosis of shock who received fluid bolus could be those who initially presented with clinical signs of shock at the outpatient department, but the signs rapidly changed after fluid bolus

Table 3 Fluid management

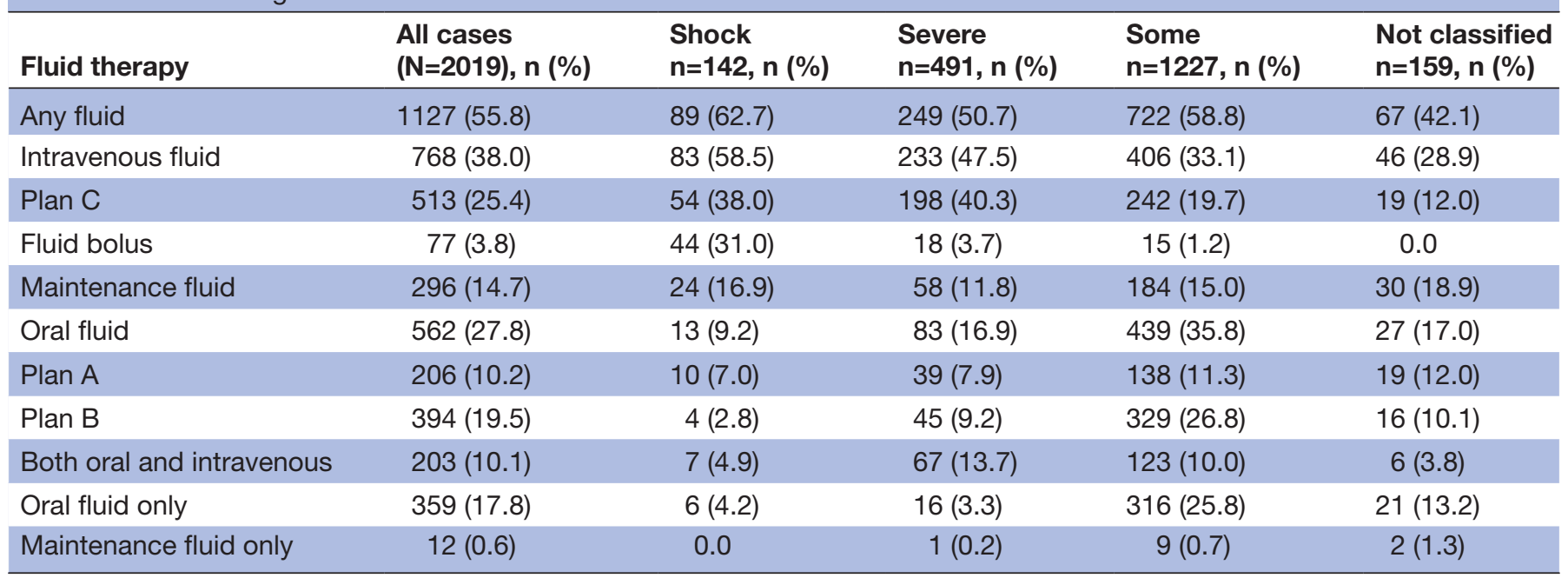


was administered before assessment at the ward, where the characteristics captured in the database were recorded. Case fatality from dehydration in children with non-diarrhoeal illnesses $(12.9 \%, 260 / 2019)$ was also higher than that seen in patients with dehydration and diarrhoea previously. ${ }^{23} 24$ Pneumonia and malaria were common underlying illnesses, and this has also been reported in previous studies. 812132526

Dehydration in patients without diarrhoea is not surprising because it may be caused by a number of mechanisms such as loss of fluids through vomiting, increased insensible losses from fever and due to high surface area to volume ratio in the under-5s who were the participants in this study. ${ }^{1}$ These mechanisms have been reported in malaria $^{12-14}$ and pneumonia, ${ }^{8}$ which are the two major underlying diagnoses in this study. While less children received rehydration therapy compared with cases with $\mathrm{DD}$, use of similar fluid management approach to that of diarrhoea cases raises concerns of potential harm in malaria, ${ }^{9}$ pneumonia ${ }^{7}$ and meningitis ${ }^{727}$ especially when vascular changes leading to fluid redistribution in vasculature may also be at play. Although this study investigated dehydration rather than impaired circulation as was done in the FEAST study, we think the findings of the FEAST study may have some relevance to this population due to potential in change in condition in the real world. Fluid bolus use resulted in increased mortality within the first 48 hours in children admitted with severe infection $(57 \%$ of whom had malaria) and impaired perfusion in the FEAST study. ${ }^{9}$ Two well-powered systematic reviews where the FEAST study was included, agreed with findings from the FEAST study. ${ }^{28}{ }^{29}$ Less frequent rehydration therapy in non-diarrhoea illnesses recorded in this study could be a result of cautious use of fluid therapy in non-diarrhoea illnesses such as pneumonia. The high case fatality could be due to underlying diagnoses, and dehydration in these cases may be a marker of severity leading to increased risk of death. It is also possible that treatment is wrongly withheld, or a wrong fluid treatment given being responsible for the higher case fatality, but this is only speculative. Fewer children with dehydration without diarrhoea received fluid therapy and it is not clear if this decision is correct and fluid regimen to use in non-diarrhoeal cases is contentious. Nevertheless, these findings warrant further attention, given the findings in the FEAST study and its significance to the study population. We have previously shown low use of fluid boluses in these hospitals, ${ }^{30}$ which is reassuring, but data analysed captured a period before widespread dissemination of the new WHO fluid guidelines, ${ }^{4}$ and results in this study are reassuring.

Hospitals in this study receive regular feedback on care processes given to admitted children, and the network also has data quality assurance procedures in place. We are therefore confident that the data are of good quality, and this was reinforced by the validation from the file linkage in this study. CIN procedures have also improved documentation of assessment, diagnosis, classification and treatments, and this allows for the analysis presented here which may be difficult to repeat in settings without activities such as done within CIN. ${ }^{31}$ However, the findings are still generalisable because of diversity of hospitals involved and use of routine data rather than those collected under research conditions.

These results highlight varied practice in the absence of clear guidance for use by frontline clinicians in resource poor settings, who are often junior clinicians. We recognise that guidelines cannot cover all imaginable clinical scenarios, but fluid treatment is quite a common practice in hospitals and guidance for this group may be necessary. However, this will only be possible after definitive studies to address their fluid therapy, given the concerns seen in the FEAST study. ${ }^{32}$ While these children did not have diarrhoea, even those with dehydration secondary to diarrhoea frequently present with other conditions where cautious fluid management is advised. ${ }^{23}$ Therefore, further studies may also be necessary to investigate appropriate fluid management for those with DD complicated by other illnesses.

\section{Limitations}

Our study was limited in several ways; some treatment might have been documented but not given, or administered but not documented, and we cannot ascertain actual administration. Use of registry data is also known for its limitations with ascertainment and selection biases being persisting concerns. We also used clinician diagnoses without checking whether these reflected correct diagnoses based on clinical signs, and there can be misdiagnosis due to errors, clinical inexperience and lack of adequate knowledge. ${ }^{33}$

\section{CONCLUSION}

Sixteen per cent of children hospitalised with dehydration do not have diarrhoea. Although dehydration is uncommon in children without diarrhoea, the case fatality is higher compared with that in children with diarrhoea. Clinicians are less likely to use fluids for treatment of dehydration when there is no diarrhoea, but they use the same fluid regime like that for diarrhoeal cases when they prescribe fluid therapy, which is potentially harmful. Efforts to promote compliance with guidance in routine clinical settings should recognise special circumstances where guidelines do not apply and are in need for further evidence.

Acknowledgements The authors thank the Ministry of Health, county health executives and all hospital management team who gave permission and supported the implementation of theClinical Information Network (CIN). We are grateful for the support provided by the Kenya Paediatric Association through their officers and membership. We also thank the hospital clinical teams on all the paediatric wards who provide care to the children for whom this project is designed. The CIN author group who contributed to the network's development, data collection, data management, implementation of audit and feedback includes Grace Irimu, Morris Ogero, Mercy Chepkirui, George Mbevi, Cynthia Khazenzi at Kenya Medical Research Institute Wellcome Trust Research Programme developed the CIN approach and database tools. The CIN authors who contributed to the conduct of the work, collection of data, and data quality assurance include Victor Juma and Samuel Ng'arng'ar (Vihiga County Hospital); Boniface Nyumbile and Roselyne Malangachi (Kakamega County Hospital); Loice Mutai, Christine Manyasi, and David Kimutai (Mbagathi County Hospital); Caren Emadau, Atieno Jowi, Cecilia Mutiso and Celia Muturi (Mama Lucy Kibaki County Hospital); Charles Nzioki and Supa Tunje 
(Machakos County Hospital); Francis Kanyingi and Agnes Mithamo (Nyeri County Hospital); Magdalene Kuria (Kisumu East County Hospital); Sam Otido and Esther Mukami Njiru (Embu County Hospital); Peninah Muthoni and Peris Njiiri (Kerugoya County Hospital); Rachel Inginia and Melab Musabi (Kitale County Hospital); Emma Sarah Namulala (Busia County Hospital); Grace Akech and Lydia Thuranira (Kiambu County Hospital).

\section{Collaborators The Clinical Information Network}

Contributors SA and ME conceptualised and designed the study with contribution from JA, DG and AA. SO collected case notes review data. SO analysed the data and drafted the initial manuscript with input from SA and other coauthors. All authors reviewed and provided input into the final version of the manuscript.

Funding This work was supported by funds from a Wellcome Trust Senior Clinical Fellowship awarded to ME (\# 207522). SA was supported by the Initiative to Develop African Research Leaders Wellcome Trust award (\# 107769). The funders had no role in study design, data collection and analysis, decision to publish or preparation of the manuscript.

Competing interests None declared.

Patient and public involvement Patients and/or the public were not involved in the design, conduct, reporting or dissemination plans of this research.

\section{Patient consent for publication Not required.}

Ethics approval The Clinical Information Network project and audit for routine care has been approved by the Kenya Medical Research Institute Scientific and Ethics Review (unit number 3459), who approved use of deidentified data for analysis and publication. Primary data belong to respective hospitals.

Provenance and peer review Not commissioned; externally peer reviewed.

Data availability statement Data may be obtained from a third party and are not publicly available. The source data are owned by the Kenyan Ministry of Health and County Governments. Users who wish to reuse the source data should make a request through the KEMRI-Wellcome Trust Research Programme Data Governance Committee.

Open access This is an open access article distributed in accordance with the Creative Commons Attribution Non Commercial (CC BY-NC 4.0) license, which permits others to distribute, remix, adapt, build upon this work non-commercially, and license their derivative works on different terms, provided the original work is properly cited, appropriate credit is given, any changes made indicated, and the use is non-commercial. See: http://creativecommons.org/licenses/by-nc/4.0/.

\section{ORCID iDs}

Sylvia Omoke http://orcid.org/0000-0003-1269-5519

Jalemba Aluvaala http://orcid.org/0000-0002-0851-3711

\section{REFERENCES}

1 Nichols DG, ed. Roger's textbook of Paediatric Intensive care. 4th edn. Philadelphia: Lippincot Williams \& Willkins, 2008.

2 WHO. Pocket book of hospital care for children: guidelines for the management of common illnesses with limited resources. 2nd edn. Geneva: World Health Organization, 2013.

3 WHO. Guidelines for the treatment of malaria. 2nd edn. Geneva: WHO, 2010.

4 Duke T. New WHO guidelines on emergency triage assessment and treatment. Lancet 2016;387:721-4.

5 Basic paediatric protocols iDOC+Africa, 2016. Available: http://www. kenyapaediatric.org/idoc/index.php/en/102-home/97-welcome-toidoc-africa.html [Accessed 2 Nov 2018].

6 Planche T. Not yet time to use mortality as an outcome in trials of intravenous fluid therapy in severe malaria. Trends Parasitol 2007;23:138-9.

7 Shann F, Germer S. Hyponatraemia associated with pneumonia or bacterial meningitis. Arch Dis Child 1985;60:963-6.

8 Dhawan A, Narang A, Singhi S. Hyponatraemia and the inappropriate ADH syndrome in pneumonia. Ann Trop Paediatr 1992;12:455-62.
9 Maitland K, Kiguli S, Opoka RO, et al. Mortality after fluid bolus in African children with severe infection. $N$ Engl $\mathrm{J}$ Med 2011;364:2483-95.

10 Liu L, Oza S, Hogan D, et al. Global, regional, and national causes of child mortality in 2000-13, with projections to inform post-2015 priorities: an updated systematic analysis. Lancet 2015;385:430-40.

11 Bianchetti MG, Thyssen HR, Laux-End R, et al. Evidence for fluid volume depletion in hyponatraemic patients with bacterial meningitis. Acta Paediatr 1996;85:1163-6.

12 English M, Waruiru C, Mwakesi R, et al. Signs of dehydration in severe childhood malaria. Trop Doct 1997;27:235-6.

13 English MC, Waruiru C, Lightowler C, et al. Hyponatraemia and dehydration in severe malaria. Arch Dis Child 1996;74:201-5.

14 Maitland K, Levin M, English M, et al. Severe P. falciparum malaria in Kenyan children: evidence for hypovolaemia. QJM 2003;96:427-34.

15 Ayieko P, Ogero M, Makone B, et al. Characteristics of admissions and variations in the use of basic investigations, treatments and outcomes in Kenyan hospitals within a new clinical information network. Arch Dis Child 2016;101:223-9.

16 Macharia PM, Giorgi E, Noor AM, et al. Spatio-temporal analysis of Plasmodium falciparum prevalence to understand the past and chart the future of malaria control in Kenya. Malar J 2018;17:340.

17 Tuti T, Bitok M, Malla L, et al. Improving documentation of clinical care within a clinical information network: an essential initial step in efforts to understand and improve care in Kenyan hospitals. BMJ Glob Health 2016;1:e000028.

18 Tuti T, Bitok M, Paton C, et al. Innovating to enhance clinical data management using non-commercial and open source solutions across a multi-center network supporting inpatient pediatric care and research in Kenya. J Am Med Inform Assoc 2016;23:184-92.

19 Irimu G, Ogero M, Mbevi G, et al. Tackling health professionals' strikes: an essential part of health system strengthening in Kenya. BMJ Glob Health 2018;3:e001136.

20 WHO. Management of the child with a serious infection or severe malnutrition: guidelines for care at the first-referral level in developing countries. Geneva: World Health Organization, 2000

21 Carcillo JA, Fields Al, Comitê de Força-Tarefa. [Clinical practice parameters for hemodynamic support of pediatric and neonatal patients in septic shock]. J Pediatr 2002;78:449-66.

22 Planche T, Onanga M, Schwenk A, et al. Assessment of volume depletion in children with malaria. PLoS Med 2004;1:e18.

23 Akech S, Ayieko P, Gathara D, et al. Risk factors for mortality and effect of correct fluid prescription in children with diarrhoea and dehydration without severe acute malnutrition admitted to Kenyan hospitals: an observational, association study. Lancet Child Adolesc Health 2018;2:516-24.

24 O'Reilly CE, Jaron P, Ochieng B, et al. Risk factors for death among children less than 5 years old hospitalized with diarrhea in rural Western Kenya, 2005-2007: a cohort study. PLoS Med 2012;9:e1001256.

25 Maitland K. Severe malaria: lessons learned from the management of critical illness in children. Trends Parasitol 2006;22:457-62.

26 Maitland K, Pamba A, Newton CRJC, et al. Response to volume resuscitation in children with severe malaria. Pediatr Crit Care Med 2003:4:426-31.

27 Duke T. Fluid management of bacterial meningitis in developing countries. Arch Dis Child 1998;79:181-5.

28 Opiyo N, Molyneux E, Sinclair D, et al. Immediate fluid management of children with severe febrile illness and signs of impaired circulation in low-income settings: a contextualised systematic review. BMJ Open 2014;4:e004934.

29 Ford N, Hargreaves S, Shanks L. Mortality after fluid bolus in children with shock due to sepsis or severe infection: a systematic review and meta-analysis. PLoS One 2012;7:e43953.

30 Mbevi G, Ayieko P, Irimu G, et al. Prevalence, aetiology, treatment and outcomes of shock in children admitted to Kenyan hospitals. BMC Med 2016;14:184.

31 Irimu G, Ogero M, Mbevi G, et al. Approaching quality improvement at scale: a learning health system approach in Kenya. Arch Dis Child 2018;103

32 Maconochie IK, Bhaumik S. Fluid therapy for acute bacterial meningitis. Cochrane Database Syst Rev 2016;11:CD004786.

33 Ogero M, Akech S, Malla L, et al. Examining which clinicians provide admission hospital care in a high mortality setting and their adherence to guidelines: an observational study in 13 hospitals. Arch Dis Child 2020;105:648-54. 